\title{
Genetic parameter estimates for the South African Mutton Merino breed
}

\author{
F.W.C. Neser ${ }^{\#}$, G.J. Erasmus and J.B. van Wyk \\ Dept of Animal Science, University of the Orange Free State, PO Box 339, Bloemfontein, 9300 \\ \#Email:Neser@landbou.uovs.ac.za
}

\section{Introduction}

The South African Mutton Merino is a dual-purpose (mutton and wool) sheep breed, that was developed by selection from the imported German Merino. The distinct possibility of a rapid increase in the volume of genetic material being exported has stressed the need for more widespread accurate genetic evaluations. Although the South African Mutton Merino was, strictly speaking, not initially developed in South Africa, the breed has undergone such a metamorphosis that it no longer bears much, if any, resemblance to its European ancestor. The need for a separate genetic characterization of this distinct South African strain is therefore evident. The aim of this study was to determine the applicable non-genetic factors and to estimate genetic parameters for several growth traits within the constraints of the field data available for the breed.

\section{Material and Methods}

A total number of 387600 pedigree and 126477 performance records were available from the South African Mutton Merino Breed Society. These records spanned a period of 25 years, from 1974 to 1999, and were obtained from 254 studs, situated throughout South Africa. All studs are genetically linked since AI is used extensively in the breed and many sires change hands annually. Animals were unfortunately weighed at only one of these intervals: 36-days, 42-days, 50-days, 100-days or 150-days. This prevents the fitting of a multi-trait model and subsequent estimation of genetic correlations.

Table 1. Description of data used in the analyses

\begin{tabular}{lrrrrr}
\hline & 36-day & 42-day & 50 -day & 100-day & 150-day \\
\hline Number of animals & 2002 & 6117 & 10254 & 63683 & 6269 \\
Number of sires & 193 & 292 & 373 & 1608 & 316 \\
Number of studs & 14 & 14 & 17 & 91 & 27 \\
Average weight $(\mathrm{kg})$ & 16.27 & 17.48 & 19.48 & 30.64 & 35.54 \\
Standard deviation $(\mathrm{kg})$ & 4.62 & 5.15 & 5.91 & 7.40 & 8.59 \\
Coefficient of variation $(\%)$ & 28.40 & 29.46 & 30.34 & 24.15 & 24.17 \\
Average age (days) & 36.76 & 43.88 & 51.05 & 102.30 & 145.68 \\
Period & $1986-1999$ & $1986-1999$ & $1986-1999$ & $1980-1999$ & $1991-1999$ \\
\hline
\end{tabular}

The 42-day weight of the lamb is generally regarded as being an indication of the milk production and nursing ability of its dam, while the 100-day weight represents the weaning weight of the lamb. The post weaning growth of the lamb is reflected in the 150-day weight of the animal. The weights (36- and 50-days) on either side of 42-days could possibly serve as an indication of the relative importance of the direct and maternal contribution at 42-days. The DFREML program of Meyer (1995) was used to estimate genetic parameters for the five traits.

\section{Results and Discussion}

The heritability estimates obtained for the five traits are presented in Table 2. 
Short paper and poster abstracts: $38^{\text {th }}$ Congress of the South African Society of Animal Science

Table 2 Heritability estimates for the five traits

\begin{tabular}{lrrrrr}
\hline & 36-day & 42-day & 50 -day & 100-day & 150-day \\
\hline Direct heritability & 0.270 & 0.366 & 0.278 & 0.185 & 0.115 \\
SE & 0.120 & 0.060 & 0.045 & 0.018 & 0.046 \\
Maternal heritability & 0.494 & 0.249 & 0.129 & 0.091 & 0.080 \\
SE & 0.487 & 0.071 & 0.068 & 0.012 & 0.123 \\
Covariance as proportion of total variance & -0.365 & -0.272 & -0.144 & -0.071 & -0.036 \\
SE & 0.250 & 0.055 & 0.049 & 0.016 & 0.070 \\
Permanent maternal environment & 0.089 & 0.162 & 0.137 & 0.099 & 0.070 \\
SE & 0.330 & 0.048 & 0.030 & 0.009 & 0.088 \\
Correlation between animal effects & -1.000 & -0.901 & -0.765 & -0.545 & -0.376 \\
\hline
\end{tabular}

Many results for weaning weight in sheep have been reported in the literature, but very few for 36day, 42-day, 50-day and 150-day weight. Only weaning weight was analyzed in the two previous studies done on this breed (Neser et al., 1998; Gray et al., 1999). Both the direct and maternal heritability estimates obtained for weaning weight in this study are lower than the two previous studies $(0.185$ vs 0.35 and 0.32 ; and 0.09 vs 0.17 and 0.15). Published South African heritability estimates for weaning weight in other breeds vary from $0.11-0.33$ for direct and $0.07-0.20$ for maternal effects (Van Wyk et al., 1993; Snyman et al., 1995; Neser et al., 1995). Other heritability estimates for weaning weight in the literature for mutton and dual purpose breeds vary between 0.05 and 0.57 (Fogarty, 1995). Only four references for 50-day weight could be obtained in the literature. No South African results are available. The heritability estimates $(0.28$ direct, 0.13-maternal) obtained in this study are in line with the results in the literature which vary from 0.05 - 0.47 for direct and 0.06 - 0.14 for maternal effects (Shrestha et al., 1985; Shrestha et al., 1986; Tosh \& Kemp, 1994; Mousa et al., 1999). It is, however, lower than those obtained by Maria et al. (1993) for 60-day weight (0.34-direct, 0.25-maternal) but higher than those obtained by Notter, 1998 in Suffolk and Polypay sheep (0.14 \& 0.08 -direct and $0.05 \& 0.07$-maternal). Although it is generally regarded by many that the 42 day weight of a lamb is an indication of the milk production of its dam, the low maternal heritability $(0.25)$, in comparison with the direct heritability (0.37), could be an indication that this assumption is flawed. These estimates are higher than the direct heritability estimate obtained by Boujenane \& Kerfal (1990) for 30-day weight in D'man sheep (0.23). It is also higher than the estimates obtained by Hagger (1998) for BlackBrown Mountain Sheep and White Alpine Sheep (0.16 \& 0.14-direct and $0.06 \& 0.10$-maternal). Only one South African study deals with 150-day weight. Snyman et al. (1995) obtained a direct heritability estimate of 0.38 and a maternal heritability of 0.17 for Afrino sheep. This is higher than the results obtained in this study ( 0.12 and 0.08 respectively). Other authors only reported direct heritabilities for 180 days weights, which vary from 0.22 - 0.43 (Dzakuma et al., 1978; Atkins, 1986; Boujenane \& Kerfal, 1990). The genetic correlation estimates between animal effects (direct and maternal) were generally highly negative. They also, as expected, decline with age. This corresponds with results obtained by Tosh \& Kemp (1994) in Polled Dorset and Romanov sheep. The high negative correlation estimate between the animal effects in all the traits are of concern, as it will hamper selection progress in all these traits. It is possible, with the inclusion of sire $\mathrm{x}$ flock-year-season interaction, to lower the correlation between the two effects (Meyer, 1997; Neser $e t$ al., 1998; Hagger, 1998). However, the data structure prevents the fitting of a sire $\mathrm{x}$ flock-year-season effect (Neser et al., 1998). The total heritability, defined as the value used to calculate the expected response to phenotypic selection, is $0.000,0.082,0.125,0.124$ and 0.101 respectively for the five traits. Not only is the negative genetic correlation unity (Table 2) but the total heritability estimate for 36-day weight is zero. This would mean that no selection progress for this trait is possible when selection takes place on the phenotypic value of the animal. The only purpose this trait would therefore serve is to give an indication of the milk production and nursing ability of the ewe. The total heritability estimates for the rest of the traits are also low, but some selection progress is possible.

\section{Conclusion}

This study provides evidence to supports the hypothesis that it is virtually impossible to genetically improve direct and maternal growth ability simultaneously applying current methods and knowledge. The apparent genetic antagonism between these two important causal components of growth needs serious further 
investigation. The limitations in the use of field data in genetic studies have also, once again, been illustrated. Breeders record weights at different lamb ages and do not regularly supply all animal records to the database. These studies, however, provide useful information on operational models and genetic parameters based on the actual data needed for predicting breeding values and is therefore of utmost importance.

\section{References}

Atkins, K.D., 1986. Anim. Prod. 43, 405.

Boujenane, I. \& Kerfal, M., 1990. Anim. Prod. 51, 173.

Dzakuma, J.M. et al., 1978. J. Anim. Sci. 47, 1015.

Fogarty, N.M., 1995. Anim. Breed. Abstr. 63, 101.

Gray, H.Q. et al., S. Afr. J. Anim. Sci. 29, 48.

Hagger, C. 1998. J. Anim. Sci. 76, 452.

Maria, G.A. et al., 1993. J. Anim. Sci. 71, 845.

Meyer, K., 1995. User Notes.

Meyer, K., 1997. Livest. Prod. Sci. 52, 187.

Mousa, E. et al., 1999. J. Anim. Sci. 77, 1659.

Neser, F.W.C. et al., 1995. S. Afr. J. Anim. Sci. 25, 65.

Neser, F.W.C. et al., 1998. S. Afr. J. Anim. Sci. 28, 179.

Notter, D.R., 1998. Livest. Prod. Sci. 55, 205.

Shrestha, J.N.B. et al., 1985. Can. J. Anim. Sci. 65(3), 575.

Shrestha, J.N.B. et al., 1986. Can. J. Anim. Sci. 66(1), 289.

Snyman, M.A. et al., Livest. Prod. Sci. 44, 229.

Tosh, J.J. \& Kemp, R.A., 1994. J. Anim. Sci. 72, 1184.

Van Wyk, J.B. et al., 1993. S. Afr. J. Anim. Sci. 23, 72. 